\title{
Medullary Thyroid Carcinoma Metastatic to the Skin: A Cutaneous Mani- festation of a Widely Disseminated Malignancy
}

\author{
C. Rodríguez-Cerdeira ${ }^{*}$, , B. Sánchez ${ }^{1}$, A. Tarrio ${ }^{2}$ and J.J. Vilata ${ }^{3}$ \\ ${ }^{I}$ Department of Dermatology, CHUVI \& University of Vigo, Vigo, Spain \\ ${ }^{2}$ Department of Pathology, CHUVI, Vigo, Spain \\ ${ }^{3}$ Department of Dermatology, University of Valencia, Valencia, Spain
}

\begin{abstract}
Metastases located in the skin from thyroid carcinoma, especially the medullary type, are rare and known to occur in the setting of disseminated neoplastic disease.

We report a case of a 72-year-old man, diagnosed as having medullary thyroid carcinoma, on whom a total thyroidectomy and removal of cervical lymph nodes were carried out. The medical treatment after surgery was ${ }^{131} \mathrm{I}$ and hormone therapy. Later, the patient received ${ }^{60} \mathrm{Co}$ teletherapy on the cervical region. On posterior examination, the patient showed a relapse of nodal metastases and pulmonary, hepatic and bone metastases. At that stage, he showed a single nodular lesion on the supraclavicular region. Therefore, a diagnosis of metastatic medullary thyroid carcinoma was made. He had received palliative treatment for the remaining metastatic lesions. During the follow-up, the patient's general condition slowly deteriorated and he died a few days after the last diagnosis. No autopsy was performed.
\end{abstract}

Keywords: Medullary thyroid carcinoma, skin mestastases, octreotide.

\section{INTRODUCTION}

Medullary thyroid carcinoma (MTC) is a rare neuroendocrine tumour of thyroid parafollicular or C cells. MTC may occur sporadically, as a familial trait without other associated tumours, or as a familial trait with other endocrine tumours in the multiple endocrine neoplasia syndromes (MEN) $2 \mathrm{~A}$ and MEN2B [1]. It represents $3-10 \%$ of all thyroid carcinomas [2]. It is responsible for $13.4 \%$ of all deaths related to the latter. Undoubtedly, the capacity to metastasize represents one of the essential peculiarities of malignant neoplasias. The cutaneous metastases of inner carcinomas are rare, thyroid carcinomas are no exception. Only very rarely, we find skin metastases from a MTC. Their diagnosis is of vital importance

Cutaneous metastases might be the last site of dissemination of a supposedly excised and treated MTC or the first manifestation of a non-diagnosed MTC. Their presence considerably worsens the disease's prognosis.

\section{CASE REPORT}

We present a case of a 72-year-old man, with no family history of thyroid carcinomas, or other endocrine tumours. In order to do this a detailed interview with his family and revision of their previous clinical histories were carried out. He had been diagnosed of a sporadic MTC nine years earlier. We did not discover other associated neoplasias. He underwent total thyroidectomy and modified radical neck dissection. He was subsequently treated with ${ }^{131} \mathrm{I}$, thyroid hormone

*Address correspondence to this author at the Department of Dermatology. CHUVI, Meixoeiro Hospital \& University of Vigo, 36200 Vigo, Galicia, Spain; Tel: 0034600536114; Fax: 0034986276416;

E-mail: carmen.rodriguez.cerdeira@sergas.es replacement therapy. Later, he received external radiotherapy with ${ }^{60} \mathrm{Co}$ teletherapy on the cervical region. Later examination revealed a relapse of nodal metastases and pulmonary, hepatic and bone metastases. He presented with serum calcitonin levels of 224,6 pg/ml. and CEA levels of 346.7 $\mathrm{ng} / \mathrm{ml}$. Therefore, he was subcutaneously treated with octreotide, $100 \mathrm{mcg} / 12 \mathrm{~h}$.

By then, a $5 \mathrm{~cm}^{2}$ hard nodular skin lesion with violet discolouration, lineal distribution with telangiectasias, and mild hyperkeratosis was noticeable in the left supraclavicular area (Fig. 1). A skin biopsy specimen from the nodular lesion revealed cell proliferation with polygonal cells without nucleoli and with homogeneous chromatin, and organoid distribution in the middle of the collagen stroma. Amyloid zones stained red. Stain for calcitonin gave positive results (Figs. 2, 3). During the follow-up, the patient's general condition slowly deteriorated and he died a few days after the final diagnosis.

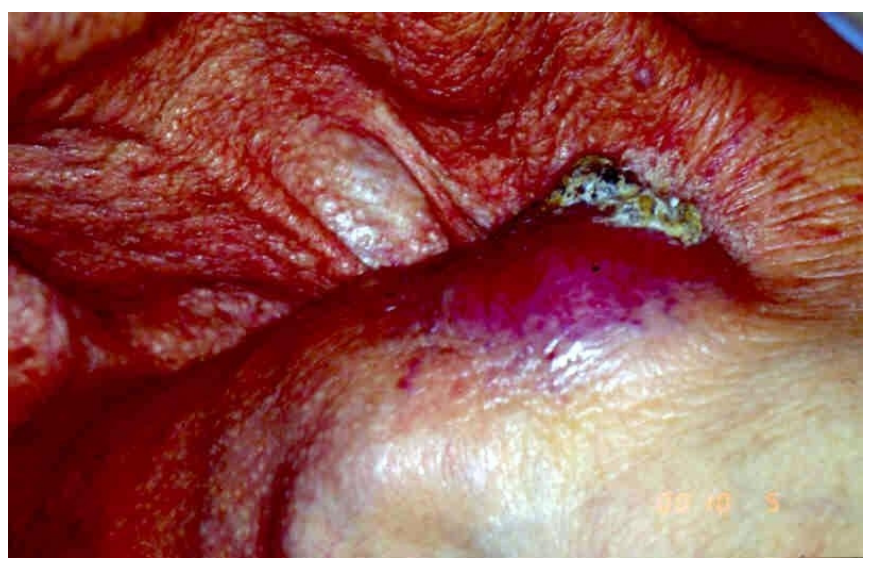

Fig. (1). Violet nodule with erythematous base on the left supraclavicular area. 


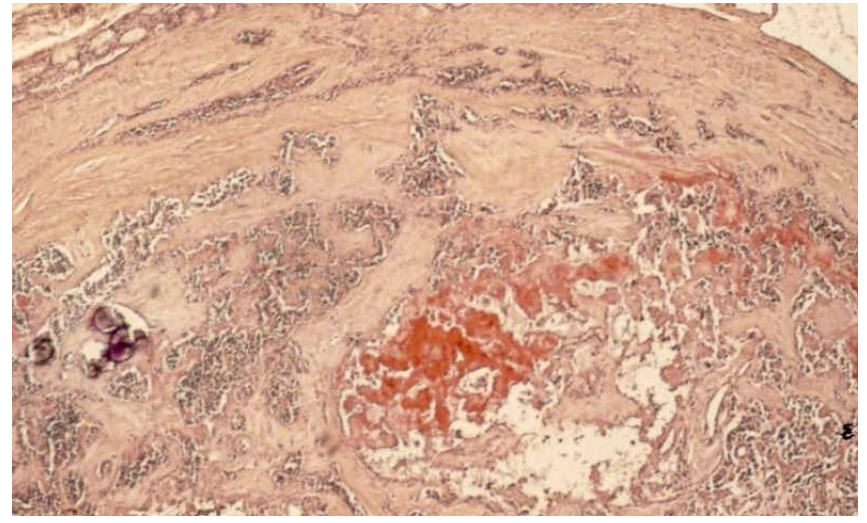

Fig. (2). Central area of calcification, and medullary tumour islets around (red Congo), original magnification $\mathrm{x} 40$.

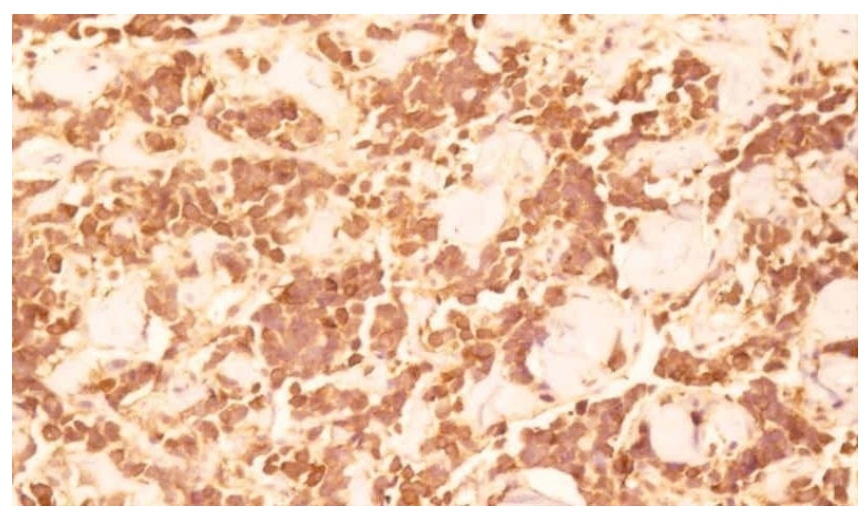

Fig. (3). Immunoperoxidase preparation showing calcitonin positive, original magnification $\mathrm{x} 400$.

MTC normally appears sporadically or within a context of well-defined genetic syndromes and is inherited as a dominant autosomal. In most of the series, the sporadic form of the disease represents between $56-90 \%$ of all cases. The average age at diagnosis in these series is 47.3 years. It is more frequent in women $[2,3]$. It may metastatize to the cervical lateral lymph nodes, liver, bone, and rarely skin and oral mucosa $[3,5-8]$. It is difficult to evaluate the real incidence of cutaneous metastases. Autopsies have been helpful in generating more accurate data between liver and bone.

\section{DISCUSSION}

To date, most thyroid carcinomas with cutaneous metastases described in the literature are of the papillary type [4], of which about $20 \%$ (11 cases), including our case, were of the medullary variant (1 MEN 2A and 10 sporadic MTC) [3, 5-8]. Most skin metastases are found in the trunk, neck and scalp. In our case it was identified in the left supra-clavicular area. The most common patterns of presentation were as a mass, an abscess or a nodule, as in our case. The tumour cells in MTC have been associated with the expression of several hormonal and non-hormonal substances stained by immunohistochemical methods. Among them, calcitonin and CEA are the most common tumour markers present in medullary thyroid carcinomas [9]. Calcitonin produced in the parafollicular $\mathrm{C}$ cells is a hormone with marked effects on calcium metabolism and its expression can be identified in $95-97 \%$ of medullary carcinomas and cutaneous metastases [9]. According to cases in the literature, the time between MTC diagnosis and the onset of cutaneous metastasis varies from four months to twelve years. In our patient, skin metastasis appeared nine years after the primary diagnosis was made. The prognosis for patients with cutaneous metastasis depends on the nature of the primary tumour and its response to treatment. Survival of the patients whose primary tumour is a medullary thyroid carcinoma is much lower than that seen with other tumours, and as such, the appearance of cutaneous metastasis may be considered an important sign of a poor prognosis. The average survival time after cutaneous metastasis diagnosis was 7.5 months $[3,5-8]$. Although this is generally the case, our patient died a few days after the final diagnosis.

Treatment of MTC depends on tumour size, location and extension of metastases, and the condition of the patient. High survival levels may be achieved with early tumour detection and subsequent total thyroidectomy with lymphadenectomy of the central area of the neck [10]. Therefore, in widespread metastatic disease, treatment is essentially palliative $[2,3]$.

\section{CONCLUSIONS}

Firstly, we want to emphasize the rarity of cutaneous metastases, specially those derived from thyroid carcinomas. From them, MTC related skin metastases are exceptional.

Secondly, we point out the bad prognosis associated with disseminated MTC.

Thirdly, we remark on the importance of immunohistochemical techniques and Congo red stain as useful tools for establishing the diagnosis and prognosis of the disease.

Finally, we want to reaffirm Drale and Molley's statement $[10,11]$, that with early detection of the tumour and subsequent total thyroidectomy with lymphadenectomy of the central area of the neck, a $100 \%$ survival rate can be attained.

\section{REFERENCES}

[1] Kebebew E, Ituarte PHG, Siperstein AE, Duh QY, Clark OH. Medullary thyroid carcinoma. Clinical characteristics, prognostic factors, and comparison of staging systems. Cancer 2000; 88: 113948.

[2] Cohen R, Buchsenschutz P, Estrade P, Gardet P, Modigliani E, et la GETC. Causes de mortalité chez les patients atteints de cancer médullaire de la thyroïde. Presse Med 1996; 25: 1819-22.

[3] Dahl PR, Brodland DG, Goellner JR, Hay ID. Thyroid carcinoma metastatic to the skin: a cutaneous manifestation of a widely disseminated malignance. J Am Acad Dermatol 1997; 36: 531-7.

[4] Rodríguez-Cerdeira MC, Lojo JL, Campos L, Oliver J. Metástasis cutánea de un carcinoma papilar de tiroides. A propósito de un caso. Rev Int Dermatol Dermocosm 2001; 4: 263-6.

[5] Runne U, Mödder G. Skin metastasis in thyroid carcinoma. Dtsch Med Wschr 1976; 101: 1831-4.

[6] Díaz JM, Fresno MF, Díaz Iglesias C, Pérez MJ, Herrero A. Metástasis cutánea de carcinoma medular de tiroides encuadrado en un síndrome de neoplasia endocrina múltiple (MEN II a). Actas Dermosifiliogr 1994; 85: 617-20.

[7] Piateill A, Fioroni M, Rubini C. Gingival metastasis from a medullary thyroid carcinoma: case report. J Periodontol 2000; 71: 112-6. 
[8] Jee MS, Chung YI, Lee MH, Choi JH, Moon KC, Koh JK, Cutaneous metastasis from medullary carcinoma of thyroid gland. Clin Exp Dermatol 2004; 28: 666- 80.

[9] Uribe M, Fenoglio-Preiser CM, Grimes M. Medullary carcinoma of the thyroid gland. Am J Surg Pathol 1985; 9: 577-94.
[10] Moley JF, Dilley WG, DeBenedetti MK. Improved results of cervical reoperation for medullary thyroid carcinoma. Ann Surg 1997; 225: 734-43.

[11] Dralle h, Damm I, Scheumann GF, Kotzerke J, Kupsch E, Geerlings $\mathrm{H}$. Compartment-oriented microdissection of regional lymph nodes in medullary thyroid carcinoma. Surg Today 1994; $24: 112-$ 21. 